\title{
The Adsorption of Radionuclides on Bitumen
}

\section{Part I: Strontium}

\author{
By L. R. Van Loon and Z. Kopajtic \\ Paul Scherrer Institute, Würenlingen and Villigen, CH-5232 Villigen PSI, Switzerland
}

(Received January 16, 1991; revised February 25, 1991)

\section{Bitumen / Adsorption / Surface complexation / Radionuclides / Strontium}

\begin{abstract}
The adsorption of ${ }^{85} \mathrm{Sr}^{2+}$ on bitumen emulsions with well characterized surfaces was studied as function of $\mathrm{pH}$ and ionic strength of the equilibrium solution. The bitumen/solution interface is negatively charged due to the deprotonation of weakly acidic carboxyl groups present at the surface. The surface group density is calculated to be $1.37 \cdot 10^{18}$ groups $/ \mathrm{m}^{2}$ and the deprotonation behaviour can be fairly well desribed by the Ionizable Surface Group Model with a $\mathrm{pK}_{\mathrm{H}}=6.6$.

$\mathrm{Sr}^{2+}$ adsorbs on the bitumen by an outer sphere complexation reaction in which one surface carboxyl group is involved in the adsorption of one $\mathrm{Sr}^{2+}$-ion. The adsorption depends on the ionic strength and $\mathrm{pH}$ of the contact solution. The higher the ionic strength, the lower the adsorption. Sorption increases with increasing $\mathrm{pH}$ due to the deprotonation of carboxyl groups.

In a cementitious environment, $\mathrm{Sr}^{2+}$ adsorption on bitumen is negligible due to the strong competition of $\mathrm{Na}^{+}, \mathrm{K}^{+}$and $\mathrm{Ca}^{2+}$ present in the cement pore water.
\end{abstract}

\section{Introduction}

Bitumen is used world wide as a matrix for incorporating low level and intermediate level radioactive waste mainly because of its good leach resistant properties. When the matrix also has a significant adsorption capacity, this can be regarded as an additional positive effect which contributes to the retention of radionuclides in the near field of a repository. It is interesting for the safety assessment studies to know whether or not radionuclides do adsorb on the matrix.

The adsorption of radionuclides on bitumen has not received much attention in the past $[1-3]$ and almost no information on the adsorption mechanisms is available. This work describes the adsorption of $\mathrm{Sr}^{2+}$ on bitumen emulsions in which the particles have well characterized surface properties as a function of $\mathrm{pH}$, ionic strength and the presence of complexing ligands.

\section{Materials and methods}

Preparation and conditioning of the bitumen emulsion

About $10 \mathrm{~g}$ of bitumen (Mexphalt 80/100) were placed in a $500 \mathrm{ml}$ flask. Approximately $400 \mathrm{ml}$ of a $10^{-3} \mathrm{M}$
$\mathrm{NaOH}(\mathrm{pH}=11)$ were added and the mixture heated to $80-90^{\circ} \mathrm{C}$ and then stirred vigorously at $24000 \mathrm{rpm}$ for 5 minutes by a high speed mixer (Ultra-Turrax, T-25; Janke and Kunkel, IKA). After cooling to room temperature, the emulsion was poured in an Erlenmeyer flask and left standing overnight.

A $50 \mathrm{ml}$ aliquot of the emulsion was placed in a dialysis bag (Dialysis Tubing-Visking, Medicell London) and equilibrated with $10^{-3} \mathrm{M} \mathrm{NaOH}$ containing different $\mathrm{NaClO}_{4}$ concentrations. The solutions were replaced 4 times at intervals of about 2 hours. After the fourth replacement, the conditioned bitumen emulsion was filtered through a $40 \mu \mathrm{m}$ nominal pore size nylon membrane (Nytal, nylon monofilament). The filtered solution was used for adsorption experiments, dry weight determination, particle size analysis and surface group density measurements.

\section{Dry weight determination}

$10 \mathrm{ml}$ of the bitumen emulsion were placed in a preweighted petri-dish and dried at $50^{\circ} \mathrm{C}$ for 24 hours. After correction for the presence of salts, the dry weight was calculated.

\section{Particle size analysis}

The particle size distribution of the emulsion was measured with a Coulter-Multisizer (Coulter Electronics Limited). The Coulter Counter determined the number and size of particles suspended in an electrically conducting liquid by forcing the suspension through a small aperture having an immersed electrode on either side. As a particle passes through the aperture, the resistance between the electrodes changes and produces a voltage pulse whose magnitude is proportional to the particle size. Isoton(II) was used as the conducting fluid and an orifice tube of $50 \mu \mathrm{m}$ was selected, which has a measurement range from 1 to $30 \mu \mathrm{m}$. The apparatus was calibrated by latex particles with a nominal diameter of $5.8 \mu \mathrm{m}$. Size distributions for particles smaller than $1 \mu \mathrm{m}$ were determined with a laser diffraction particle size distribution analyzer (Horiba LA-500). This apparatus had a measurement range from $0.1 \mu \mathrm{m}$ to $200 \mu \mathrm{m}$. The specific surface 
area (SSA) was calculated from the size distributions assuming the particles to be spherical.

\section{Surface group density determination}

The functional group density was determined by the adsorption of $\mathrm{Co}\left(\mathrm{NH}_{3}\right)_{6}^{3+}$ on the bitumen surface. This technique has recently be used successfully to determine the functional group capacity of humic acids [4] and in previous studies to measure the cation exchange capacities of metal oxides [5], clay minerals [6] and polyacrylic acids [7].

$\mathrm{Co}\left(\mathrm{NH}_{3}\right)_{6}^{3+}$ is stable in aqueous solutions between $\mathrm{pH} 2$ and 12. It adsorbs only due to Coulombic interaction and a charge reversal due to over-equivalent adsorption is excluded [5]. The negative charge on the surface is almost completely neutralized by the electrostatically adsorbed $\mathrm{Co}\left(\mathrm{NH}_{3}\right)_{6}^{3+}$. One mole of adsorbed $\mathrm{Co}\left(\mathrm{NH}_{3}\right)_{6}^{3+}$ represents three moles of negative charges on the surface $[4,5,7] . \mathrm{Co}\left(\mathrm{NH}_{3}\right)_{6}^{3{ }^{+}}$can therefore be used very well to determine the functional group density on bitumen under conditions where they are completely dissociated (high $\mathrm{pH}$ ).

An adsorption isotherm of $\mathrm{Co}\left(\mathrm{NH}_{3}\right)_{6}^{3+}$ on bitumen was determined. $20 \mathrm{ml}$ aliquots of the bitumen emulsion, conditioned in $10^{-3} \mathrm{M} \mathrm{NaOH}(\mathrm{pH}=11)$, were placed in teflon centrifuge tubes (Oak Ridge Type, $50 \mathrm{ml}$ ) and different volumes of a solution containing $10^{-4} \mathrm{M} \mathrm{Co}\left(\mathrm{NH}_{3}\right)_{6}^{3+}$ and $10^{-3} \mathrm{M} \mathrm{NaOH}$ were added. The volume in each centrifuge tube was then made up to $30 \mathrm{ml}$ by $10^{-3} \mathrm{M} \mathrm{NaOH}$. The mixtures were shaken end-over-end for 24 hours at room temperature. After equilibration, the solutions were centrifuged at $11000 \mathrm{~g}$ (Heraeus Sepatech, Biofuge 17S) for 30 minutes. The clear supernatant was analyzed for Co by ICP-AES. The amount of $\mathrm{Co}\left(\mathrm{NH}_{3}\right)_{6}^{3+}$ adsorbed was calculated from the difference in Co concentration before and after equilibrium.

\section{Adsorption of ${ }^{85} \mathrm{Sr}^{2+}$}

$20 \mathrm{ml}$ aliquots of the bitumen emulsion, conditioned in $10^{-3} \mathrm{M} \mathrm{NaOH}$ and containing different concentrations of $\mathrm{NaClO}_{4}$ in the range $10^{-3} \mathrm{M}$ and $9 \cdot 10^{-3} \mathrm{M}$, were transferred to the $50 \mathrm{ml}$ teflon centrifuge tubes. $5 \mathrm{ml}$ of the equilibrium solution, spiked with ${ }^{85} \mathrm{Sr}^{2+}$, were added. The final $\mathrm{Sr}^{2+}$ concentration was $10^{-10} \mathrm{M}$. The mixtures were shaken end-overend for 24 hours whereafter phase separation was performed by centrifugation at $11000 \mathrm{~g}$ for 30 minutes. $2 \mathrm{ml}$ of the clear supernatant were sampled and analyzed for ${ }^{85} \mathrm{Sr}$ by liquid scintillation counting (Packard, Tricarb $2250 \mathrm{CA}$ ) using Instagel (Packard) as the scintillation cocktail. The amount of $\mathrm{Sr}^{2+}$ adsorbed was calculated from the difference in concentration before and after equilibrium.

To study the $\mathrm{pH}$ dependency of the $\mathrm{Sr}^{2+}$-adsorption, bitumen emulsions were equilibrated in dialysis bags at different $\mathrm{pH}$ values between 7 and 11 . Because of the low buffering capacity of the bitumen emulsion, $5 \cdot 10^{-4} \mathrm{M}$ TRIS (Tris(hydroxymethyl)-aminomethane) was used to buffer the $\mathrm{pH}$ in the range 7 to 8.6. Beyond $\mathrm{pH} \mathrm{9,} \mathrm{the} \mathrm{pH}$ was adjusted with $\mathrm{NaOH}$ to the desired value. The ionic strength of the solutions was fixed at $0.001 \mathrm{M}$. The same adsorption procedure was used as described earlier.

The effect of complexing substances on the adsorption of $\mathrm{Sr}^{2+}$ on bitumen was studied by adding NTA (nitrilotriacetic acid) to the liquid phase. The concentration of NTA was varied from $10^{-6} \mathrm{M}$ to $10^{-4} \mathrm{M}$. The total $\mathrm{Na}^{+}$concentration amounted to 1.5 $\cdot 10^{-3} \mathrm{M}$ and the $\mathrm{pH}$ was fixed at 11 . The adsorption was performed in the same way as described above.

\section{Results and discussion}

The emulsification described previously yields bitumen-in-water emulsions with $0.2-0.3 \%$ dry matter content. The particle diameter ranges from 0.1 to $30 \mu \mathrm{m}$, resulting in a specific surface area of $3.5-4.5$ $\mathrm{m}^{2} / \mathrm{g}$.

The negative surface charge of the bitumen is caused by the deprotonation of carboxyl groups at the bitumen/water interface. The electric properties of the interface can be explained by the Ionizable SurfaceGroup Model [8]. A brief description of the model is given here.

For the deprotonation reaction of a carboxyl group on a surface:

$$
\mathrm{RCOOH} \rightleftharpoons \mathrm{RCOO}^{-}+\mathrm{H}^{+}
$$

the deprotonation constant is given by:

$$
\mathrm{K}_{\mathrm{H}}=\frac{\left\{\mathrm{RCOO}^{-}\right\}\left[\mathrm{H}^{+}\right]_{\mathrm{s}}}{\{\mathrm{RCOOH}\}}
$$

where $\left[\mathrm{H}^{+}\right]_{s}$ is the concentration of hydrogen ions close to the surface in mol/l. The concentration of protonated and deprotonated groups on the surface is expressed as groups $/ \mathrm{cm}^{2}$. The concentration of $\mathrm{H}^{+}$on the surface $\left[\mathrm{H}^{+}\right]_{s}$ is related to the bulk $\mathrm{H}^{+}$concentration $\left[\mathrm{H}^{+}\right]_{\mathrm{b}}$ by the Boltzmann equation:

$\left[\mathrm{H}^{+}\right]_{\mathrm{s}}=\left[\mathrm{H}^{+}\right]_{\mathrm{b}} \exp \left(-Y_{0}\right)$

where $Y_{0}$ is the reduced surface potential, defined as $Y_{0}=\frac{e \psi_{0}}{k T}$

$$
\text { with: } \begin{aligned}
e & =\text { elementary charge }\left(1.6 \cdot 10^{-19} \mathrm{C}\right) \\
\psi_{0} & =\text { surface potential }(\mathrm{V}) \\
k & =\text { Boltzmann constant }\left(1.38 \cdot 10^{-23} \mathrm{JK}^{-1}\right) \\
T & =\text { absolute temperature }(\mathrm{K}) .
\end{aligned}
$$

As the potential $\psi_{0}$ is negative for bitumen, the term $\exp \left(-Y_{0}\right)>1$, and this implies that the hydrogen ion concentration on the surface is higher than the hydrogen ion concentration of the bulk solution, or, the surface $\mathrm{pH}$ is lower than the solution $\mathrm{pH}$. This phenomenon has been investigated and described earlier by Danielli [9]. The difference in $\mathrm{pH}$ between 
surface and bulk solution can amount to several $\mathrm{pH}$ units. For instance, when the surface potential $\psi_{0}$ equals $-200 \mathrm{mV}$, the $\mathrm{pH}$ of the surface is $4 \mathrm{pH}$ units lower than the $\mathrm{pH}$ of the bulk solution. Weakly acidic functional groups at solid-liquid interfaces display an apparently acidic character arising from, and determined in magnitude by, the electrical potential $\psi_{0}$ generated upon ionization of the interface. As a result, the dissociation of the weakly acidic surface groups will only be complete at higher $\mathrm{pH}$ values in solution than would be the case for a monomeric weak acid in solution [10].

The surface charge of the bitumen is given by:

$$
\sigma_{0}=-e \cdot\left\{\mathrm{RCOO}^{-}\right\}
$$

and the total surface density of functional groups $\left(N_{\mathrm{s}}\right.$, groups $/ \mathrm{cm}^{2}$ ) is:

$$
N_{\mathrm{s}}=\left\{\mathrm{RCOO}^{-}\right\}+\{\mathrm{RCOOH}\} \text {. }
$$

The surface charge $\left(\sigma_{0}, \mathrm{C} / \mathrm{cm}^{2}\right)$ can thus be written as:

$$
\sigma_{0}=\frac{-e N_{\mathrm{s}}}{1+\left(\left[\mathrm{H}^{+}\right]_{\mathrm{b}} / \mathrm{K}_{\mathrm{H}}\right) \exp \left(-Y_{0}\right)} .
$$

The surface charge has to be neutralized by the charge in the diffuse electrical double layer $\left(\sigma_{\mathrm{d}}, \mathrm{C} / \mathrm{cm}^{2}\right)$ :

$$
\sigma_{0}=-\sigma_{\mathrm{d}}
$$

The charge density in the diffuse double layer can be related to the surface potential by applying the GouyChapman theory:

$$
\sigma_{\mathrm{d}}=-(8 n \varepsilon k T)^{1 / 2} \sinh \left(z Y_{0} / 2\right)
$$

with: $n=$ number of counter ions per unit volume $\left(\mathrm{cm}^{-3}\right)$

$z=$ valency of the counter ions

$\varepsilon=$ permittivity of the medium $\left(\mathrm{CV}^{-1} \mathrm{~cm}^{-1}\right)$.

Combination of equations (6) and (8) provides an explicit relationship between surface charge and surface potential as a function of $\mathrm{pH}_{\mathrm{b}}$, the salt concentration and the amount of functional groups $N_{\mathrm{s}}$ on the surface:

$$
\begin{aligned}
\mathrm{pH}_{\mathrm{b}}= & -Y_{0} / 2.303 \\
& +\mathrm{pK}_{\mathrm{H}}-\log \left(\frac{\theta}{\sinh \left(z Y_{0} / 2\right)}-1\right)
\end{aligned}
$$

where $\theta=\frac{-e N_{\mathrm{s}}}{(8 n \varepsilon k T)^{1 / 2}}$.

This relationship enables the surface potential at a given $\mathrm{pH}_{\mathrm{b}}$, ionic strength and functional group density to be calculated. The corresponding $\sigma_{0}$ can be obtained by applying equation (8), assuming that $\sigma_{0}=-\sigma_{\mathrm{d}}$. Figure 1 displays the relationship between the level of dissociation $\alpha$ and the bulk $\mathrm{pH}_{\mathrm{b}}$ as a function of the salt concentration in the solution for a functional group density on the surface of $1.37 \cdot 10^{18}$ groups $/ \mathrm{m}^{2}$, with $\alpha$ :

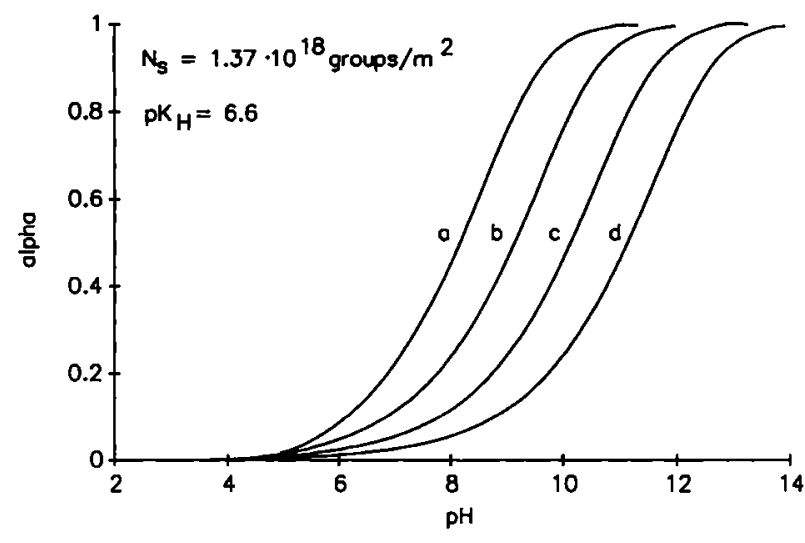

Fig. 1. Deprotonation of surface carboxyl groups on bitumen as a function of $\mathrm{pH}$. Surface group density: $1.37 \cdot 10^{18} \mathrm{groups} / \mathrm{m}^{2}$; $\mathrm{pK}_{\mathrm{H}}=6.6$. a) $\mathrm{I}=0.1 \mathrm{M}$; b) $\mathrm{I}=0.01 \mathrm{M}$; c) $\mathrm{I}=0.001 \mathrm{M}$; d) $\mathrm{I}=0.0001 \mathrm{M}$

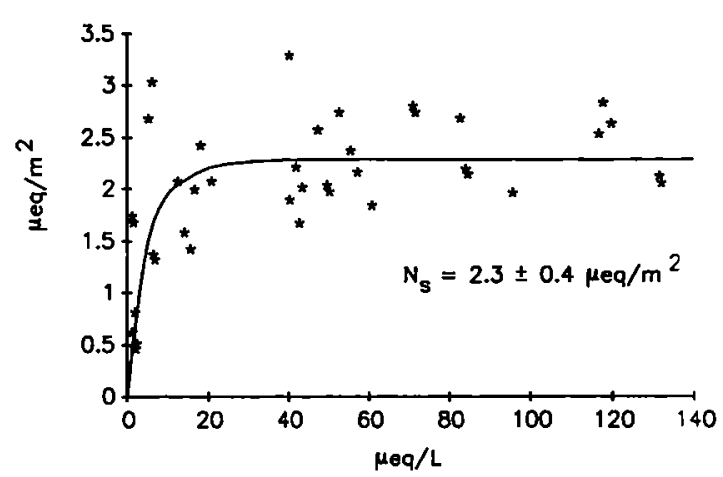

Fig. 2. Adsorption isotherm of $\mathrm{Co}\left(\mathrm{NH}_{3}\right)_{6}^{3+}$ on bitumen at $\mathrm{pH}=11\left(\mathrm{NaOH} 10^{-3} \mathrm{M}, T=20^{\circ} \mathrm{C}\right) . N_{\mathrm{s}}=2.3 \pm 0.4 \mu \mathrm{eq} / \mathrm{m}^{2}=$ $1.37 \cdot 10^{18}$ groups $/ \mathrm{m}^{2}$.

$$
\alpha=-\frac{\sigma_{0}}{e \cdot N_{\mathrm{s}}} .
$$

It is clear that the deprotonation behaviour of the carboxyl groups is complex and depends strongly on the surface group density and ionic strength of the medium.

Figure 2 shows the adsorption isotherm of Co $\left(\mathrm{NH}_{3}\right)_{6}^{3+}$ on bitumen. The adsorption isotherm shows a maximum adsorption level of $2.3 \pm 0.4 \mu \mathrm{eq} /$ $\mathrm{m}^{2}$. This corresponds to a carboxyl group density of $1.37 \cdot 10^{18}$ groups $/ \mathrm{m}^{2}$. From Fig. 1 we can see that at $\mathrm{pH}=11$ and $\mathrm{I}=0.001 \mathrm{M}$, not all the carboxyl groups have been deprotonated. Adsorption of $\mathrm{Co}\left(\mathrm{NH}_{3}\right)_{6}^{3+}$, however, causes the surface potential to become less negative with the consequence that a complete deprotonation occurs at a $\mathrm{pH}$ value lower than shown in Fig. 1. The maximum adsorption level of $\mathrm{Co}\left(\mathrm{NH}_{3}\right)_{6}^{3+}$ thus represents the surface group density. The value of the functional group density given here is in good agreement with those reported in the literature [8]. The latter values, however, were not determined directly but were estimated by modelling experimental results of electrophoretic movement of bitumen particles. 


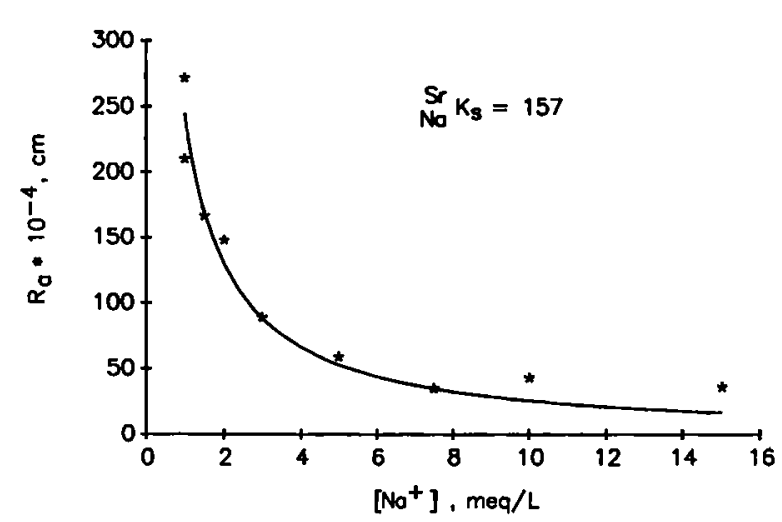

Fig. 3. Adsorption of $\mathrm{Sr}^{2+}$ on bitumen as a function of the $\mathrm{Na}^{+}$ concentration in the liquid phase at $\mathrm{pH}=11$. ${ }^{*}$ : experimental points, - : calculated from equation (22).

Figure 3 shows the adsorption of ${ }^{85} \mathrm{Sr}^{2+}$ as function of the $\mathrm{Na}^{+}$concentration in the equilibrium solution at a $\mathrm{pH}=11$. The concentration ratio $\left(R_{\mathrm{a}}^{\mathrm{Sr}}, \mathrm{cm}\right)$ decreases with increasing $\mathrm{Na}^{+}$concentration. The concentration ratio is defined as:

$$
R_{\mathrm{a}}^{\mathrm{Sr}}=\frac{\mathrm{Sr} \text { adsorbed }}{\text { Sr in solution }}=\frac{\mu \mathrm{mol} \mathrm{Sr} / \mathrm{cm}^{2}}{\mu \mathrm{mol} \mathrm{Sr} / \mathrm{cm}^{3}} .
$$

Initially, the adsorption of $\mathrm{Sr}^{2+}$ was assumed to be an ion exchange process. The heterovalent ion exchange reaction can be written as follows:

$$
2 \overline{\mathrm{Na}^{+}}+\mathrm{Sr}^{2+} \rightleftharpoons \overline{\mathrm{Sr}^{2+}}+2 \mathrm{Na}^{+} \text {. }
$$

The selectivity coefficient is defined by:

$$
\underset{\mathrm{Na}}{\mathrm{Sr}} K_{\mathrm{c}}=\frac{z_{\mathrm{Sr}} \cdot\left[\mathrm{Na}^{+}\right]^{2} \cdot \gamma_{\mathrm{Na}}^{2}}{z_{\mathrm{Na}}^{2} \cdot\left[\mathrm{Sr}^{2+}\right] \cdot \gamma_{\mathrm{Sr}}}
$$

with: $z_{\mathrm{Sr}}$ and $z_{\mathrm{Na}}$

$=$ fractional occupancy of the surface by $\mathrm{Sr}^{2+}$ and $\mathrm{Na}^{+}$

$\left[\mathrm{Sr}^{2+}\right]$ and $\left[\mathrm{Na}^{+}\right]=$concentration of $\mathrm{Sr}^{2+}$ and $\mathrm{Na}^{+}$in solution $\left(\mu \mathrm{mol} / \mathrm{cm}^{3}\right)$

$$
\begin{aligned}
\overline{\mathrm{Na}^{+}} \text {and } \overline{\mathrm{Sr}^{2+}=} & \text { amount of } \mathrm{Na}^{+} \text {and } \mathrm{Sr}^{2+} \\
& \text { adsorbed }\left(\mu \mathrm{mol} / \mathrm{cm}^{2}\right) \\
= & \text { activity coefficient of } \\
& \mathrm{Na}^{+} \text {and } \mathrm{Sr}^{2+} \text { in solu- } \\
& \text { tion. }
\end{aligned}
$$

Since we are dealing with a system containing a macroelectrolyte $\mathrm{Na}^{+}$and a trace element $\mathrm{Sr}^{2+}$, the composition of the bitumen surface does not change significantly when $\mathrm{Sr}^{2+}$ adsorbs. The activity coefficient ratio of the adsorbed species is constant and is included in the ${ }_{\mathrm{N} a}^{\mathrm{Sr}} K_{\mathrm{c}}$ value [11]. The aqueous activity coefficient ratio can be calculated from the extended Debye-Hückel [12] theory and is denoted by $\Gamma$ in the subsequent equations. The term $z_{\mathrm{Sr}}$ can be replaced by Sr/CEC:

$$
\underset{\mathrm{Na}}{\mathrm{Sr}} K_{\mathrm{c}}=\frac{\overline{\mathrm{Sr}} / \mathrm{CEC} \cdot\left[\mathrm{Na}^{+}\right]^{2}}{z_{\mathrm{Na}}^{2} \cdot 2 \cdot\left[\mathrm{Sr}^{2+}\right]} \cdot \Gamma
$$

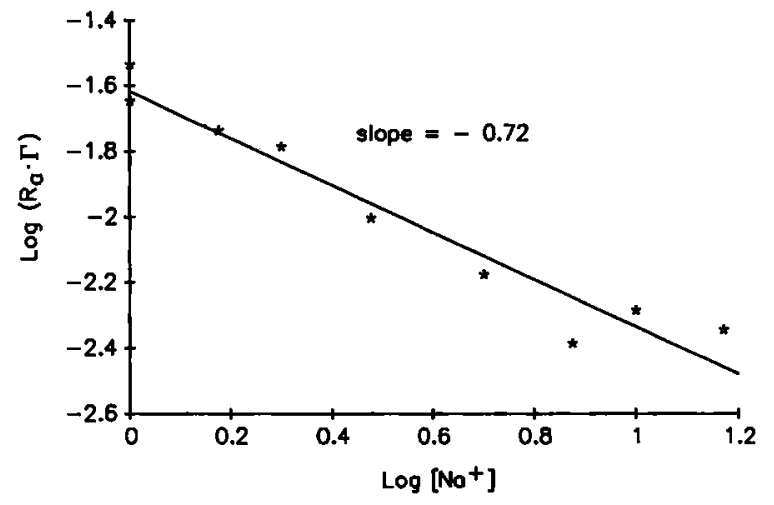

Fig. 4. Log-log plot of $K^{\mathrm{Sr}} \cdot \Gamma$ as a function of $m_{\mathrm{Na}} * *$ : experimental points; - : regression analysis.

with $\Gamma=\gamma_{\mathrm{Na}}^{2} / \gamma_{\mathrm{Sr}}$ and CEC is the amount of deprotonated carboxyl groups or the actual cation exchange capacity.

The factor 2 in equation (14) is introduced because the concentration of $\mathrm{Sr}^{2+}$ on the surface is expressed on equivalent basis.

Since $z_{\mathrm{Na}}=1$ at trace level occupancy of $\mathrm{Sr}^{2+}$ and $\overline{\mathrm{Sr}} /\left(2 \cdot\left[\mathrm{Sr}^{2+}\right]\right)=R_{\mathrm{a}}^{\mathrm{Sr}}(\mathrm{cm})$, equation $(14)$ can be written as:

$$
\underset{\mathrm{Na}}{\mathrm{Sr}} K_{\mathrm{c}}\left(z_{\mathrm{Sr}} \rightarrow 0\right)=\frac{R_{\mathrm{a}}^{\mathrm{Sr}} \cdot\left[\mathrm{Na}^{+}\right]^{2}}{\mathrm{CEC}} \cdot \Gamma
$$

or

$$
\begin{aligned}
& R_{\mathrm{a}}^{\mathrm{Sr}} \cdot \Gamma=\frac{\underset{\mathrm{Na}}{\mathrm{Sr}} K_{\mathrm{c}} \cdot \mathrm{CEC}}{\left[\mathrm{Na}^{+}\right]^{2}} \\
& \log \left(R_{\mathrm{a}}^{\mathrm{Sr}} \cdot \Gamma\right)=\log _{\mathrm{Na}}^{\mathrm{Sr}} K_{\mathrm{c}}+\log \mathrm{CEC}-2 \cdot \log \left[\mathrm{Na}^{+}\right] .
\end{aligned}
$$

In case of a pure ion exchange process, the log-log plot of $R_{\mathrm{a}}^{\mathrm{Sr}} \cdot \Gamma$ as a function of $\left[\mathrm{Na}^{+}\right]$yields a straight line with a slope -2 . Figure 4 represents such a $\log -\log$ plot. The slope of the straight line equals -0.72 instead of -2 . As this is close to -1 , it can be concluded that $1 \mathrm{~mol}$ of $\mathrm{Na}^{+}$is exchanged by $1 \mathrm{~mol}$ of $\mathrm{Sr}^{2+}$. This observation thus suggests that the adsorption of $\mathrm{Sr}^{2+}$ on bitumen is not a stoichiometric ion exchange process, but has a specific interaction character.

If we assume that the reaction of $\mathrm{Sr}^{2+}$ with the bitumen surface (carboxyl group) can be written as:

$$
\mathrm{RCOONa}+\mathrm{Sr}^{2+} \rightleftharpoons \mathrm{RCOOSr}^{+}+\mathrm{Na}^{+}
$$
then

$$
\underset{\mathrm{Na}}{\mathrm{Sr}} K_{\mathrm{s}}=\frac{\left\{\mathrm{RCOOSr}^{+}\right\} \cdot\left[\mathrm{Na}^{+}\right] \cdot \gamma_{\mathrm{Na}}}{\{\mathrm{RCOONa}\} \cdot\left[\mathrm{Sr}^{2+}\right] \cdot \gamma_{\mathrm{Sr}}}
$$

Since we are dealing with trace amounts of $\mathrm{Sr}^{2+}$, the composition of the surface does not change significantly when $\mathrm{Sr}^{2+}$ adsorbs. The surface charge and potential are completely determined by the $\mathrm{pH}$ and the $\mathrm{Na}^{+}$concentration in solution. Consequently, $\{\mathrm{RCOONa}$ \} equals the actual CEC of the bitumen. As $R_{\mathrm{a}}^{\mathrm{Sr}}=\left\{\mathrm{RCOOSr}^{+}\right\} /\left[\mathrm{Sr}^{2+}\right]$, equation (19) takes the form: 


$$
\underset{\mathrm{Na}}{\mathrm{Sr}} K_{\mathrm{s}}\left(z_{\mathrm{Sr}} \rightarrow 0\right)=\frac{R_{\mathrm{a}}^{\mathrm{Sr}} \cdot\left[\mathrm{Na}^{+}\right]}{\mathrm{CEC}} \cdot \Gamma
$$

and

$$
R_{\mathrm{a}}^{\mathrm{Sr}}=\frac{\stackrel{\mathrm{Sr}}{\mathrm{Sr}} K_{\mathrm{s}} \cdot \mathrm{CEC}}{\left[\mathrm{Na}^{+}\right] \cdot \Gamma}
$$

where $\Gamma=\gamma_{\mathrm{Na}} / \gamma_{\mathrm{sr}}$.

Fig. 1 shows that the deprotonation of the surface carboxyl groups depends strongly on the ionic strength below $\mathrm{pH}=13$. Consequently, the CEC cannot be considered to be constant. Since $\mathrm{CEC}=\alpha \cdot \mathrm{CEC}_{\max }$, equation (21) is modified in:

$$
R_{\mathrm{a}}^{\mathrm{Sr}}=\frac{\stackrel{\mathrm{N}}{\mathrm{a}}_{\mathrm{a}} K_{\mathrm{s}} \cdot \alpha \cdot \mathrm{CEC}_{\max }}{\left[\mathrm{Na}^{+}\right] \cdot \Gamma}
$$

where: $\alpha=$ degree of dissociation.

The value of $\alpha$ can be calculated for specific $\mathrm{pH}$ and I values by applying equation (7), (8), (9) and (10).

The solid line in Fig. 3 shows a least square fit of the experimental $R_{\mathrm{a}}^{\mathrm{Sr}}(\mathrm{cm})$ by equation (22). The value of ${ }_{\mathrm{Na}}^{\mathrm{Sr}} K_{\mathrm{s}}$ was derived from this least square fit and equals $157 \pm 7$. The intrinsic deprotonation constant $\left(\mathrm{pK}_{\mathrm{H}}\right)$ to calculate $\alpha$ was 6.6 and the $\mathrm{CEC}_{\max }$ was taken $2.3 \mu \mathrm{eq} / \mathrm{m}^{2}$. The experimental data can be reasonably good described by equation (22). In the model it has been assumed that one carboxyl group reacts with one $\mathrm{Sr}^{2+}$ ion to form a surface complex (or surface ionpair). As the adsorption depends on the $\mathrm{Na}^{+}$concentration in solution, the complex is an outer-sphere complex. This means that the complex formation is caused by an electrostatic attraction between ligand and metal atom, both of which conserve their hydration sphere [13]. The $\mathrm{Sr}^{2+}$ ion is thus still located in the diffuse part of the double layer and not in the Stern layer.

Evidence for a complexation reaction with one surface carboxyl group only is provided by the surface group density. The functional group density is calculated to be $1.37 \cdot 10^{18}$ groups $/ \mathrm{m}^{2}$ or 1.37 groups $/ \mathrm{nm}^{2}$. One carboxyl group is thus localized on a surface of $0.7 \mathrm{~nm}^{2}$. The mean distance between adjacent carboxyl groups equals $\pm 0.9 \mathrm{~nm}$, which corresponds to $4 \mathrm{C}-\mathrm{C}$ bonds. This distance is too large to allow a chelation reaction with two carboxyl groups.

This conclusion is also supported by the observation that the stability constants of complexes of bicarboxylic acids and metals decrease with increasing distance between the two carboxylic groups. As soon as the carboxyl groups are separated by two or more C-atoms, the stability constant is $\operatorname{low}(\log K=2)$ and changes little with increasing distance [14].

Figure 5 shows the adsorption of $\mathrm{Sr}^{2+}$ on bitumen $\left(R_{\mathrm{a}}^{\mathrm{Sr}}\right)$ as a function of the $\mathrm{pH}$ of the liquid phase. As expected, the adsorption is lower for lower $\mathrm{pH}$ values. The solid line in Fig. 5 shows the variation of $R_{\mathrm{a}}^{\mathrm{Sr}}$ as a function of $\mathrm{pH}$ as calculated from equation (22). The value of $\mathrm{Sr}_{\mathrm{N}} K_{\mathrm{s}}$ was derived from this least square plot and equals $139 \pm 8$. There is a good agreement between the calculated and experimental values. A good fit

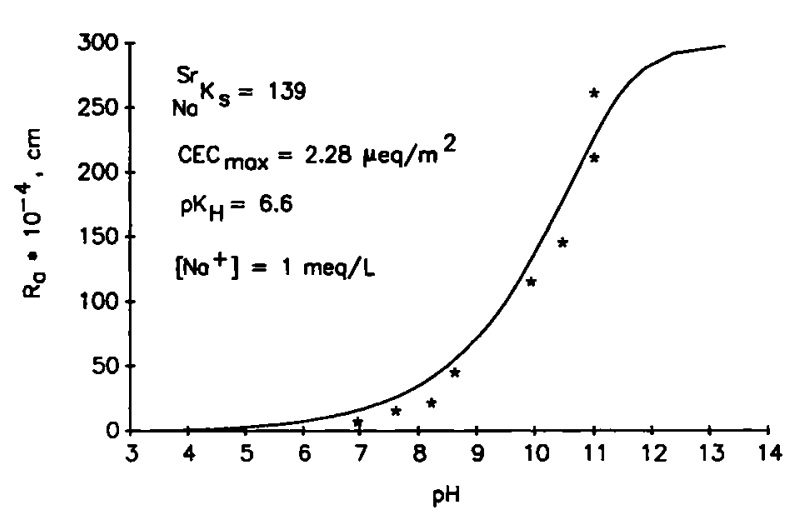

Fig. 5. Adsorption of $\mathrm{Sr}^{2+}$ on bitumen as function of $\mathrm{pH}$ at $I=0.001$ M. * : experimental points; - : calculated from equation (22).

value of the deprotonation constant $\mathrm{pK}_{\mathrm{H}}$ for the experimental data in Figure 5 was found to be 6.6. This is somewhat greater then the typical values of 4.5 to 4.8 quoted in the literature for surface carboxyl groups and the $\mathrm{pK}_{\mathrm{H}}$ value of 4.5 calculated by Takamura and Chow [8] for carboxyl groups on bitumen. A reasonable explanation for this difference cannot be given at the moment because no information is available on the nature and chemical environment of the carboxyl groups on the bitumen surface. A value of 6.6 , on the other hand, is not an implausible value. The $\mathrm{pK}_{\mathrm{H}}$ values observed for the carboxyl groups of different compounds in solution have a Gaussian distribution, exhibiting values from 0.5 to 8.5 [15].

As soon as competing complexation reactions (hydrolysis, ion pair formation, complexation with humic acids and organics such as EDTA, DTPA, NTA ...) occur in the liquid phase, the above model must be extended to account for their influence.

Assume that the following 1:1 complexation reaction takes place in the liquid phase:

$$
\mathrm{Sr}^{2+}+\mathrm{L}^{2-} \rightleftharpoons \mathrm{SrL} \text {. }
$$

The stability constant of the complex is defined as:

$$
K_{\mathrm{SrL}}=\frac{[\mathrm{SrL}]}{\left[\mathrm{Sr}^{2+}\right]\left[\mathrm{L}^{2-}\right]}
$$

The total concentration of $\mathrm{Sr}$ is:

$$
\begin{aligned}
{[\mathrm{Sr}]_{\mathrm{tot}} } & =\left[\mathrm{Sr}^{2+}\right]+[\mathrm{SrL}] \\
& =\left[\mathrm{Sr}^{2+}\right]+K_{\mathrm{SrL}} \cdot\left[\mathrm{Sr}^{2+}\right] \cdot\left[\mathrm{L}^{2-}\right] \\
& =\left[\mathrm{Sr}^{2+}\right]\left(1+K_{\mathrm{SrL}} \cdot\left[\mathrm{L}^{2-}\right]\right) .
\end{aligned}
$$

Hydrolysis of $\mathrm{Sr}^{2+}$ can be neglected. At a pH of 11 , $99.6 \%$ of the $\mathrm{Sr}$ is present as $\mathrm{Sr}^{2+}$ and only $0.4 \%$ as $\mathrm{Sr}(\mathrm{OH})^{+}$.

As shown previously, the adsorption of $\mathrm{Sr}^{2+}$ can be described by:

$$
\underset{\mathrm{Na}}{\mathrm{Sr}} K_{\mathrm{s}}=\frac{\left\{\mathrm{RCOOSr} r^{+}\right\} \cdot\left[\mathrm{Na}^{+}\right]}{\{\mathrm{RCOONa}\} \cdot\left[\mathrm{Sr}^{2+}\right]} \cdot \Gamma .
$$




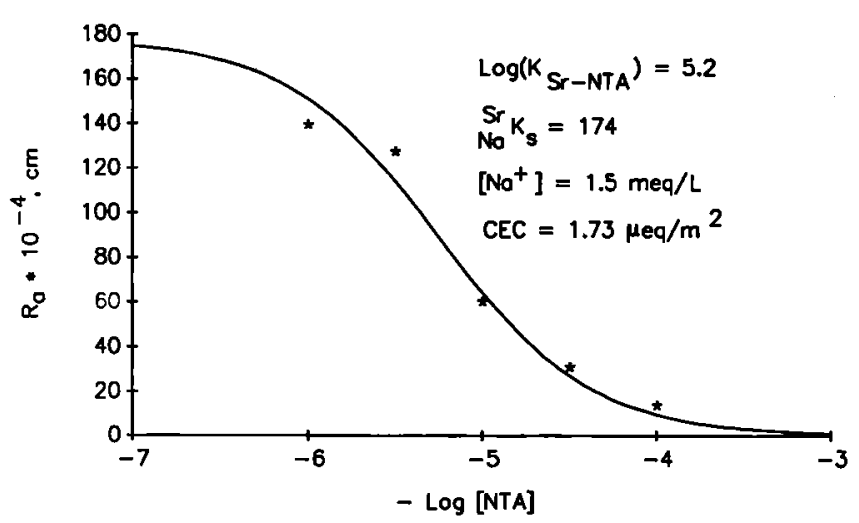

Fig. 6. Adsorption of $\mathrm{Sr}^{2+}$ on bitumen at $\mathrm{pH}=11$ and $\mathrm{I}=$ $0.0015 \mathrm{M}$ as a function of [NTA] in the liquid phase. *: experimental results; - : calculated from equation (30).

Table 1. Overview of ${ }_{\mathrm{Na}}^{\mathrm{S}} K_{\mathrm{s}}$ values obtained from different experiments

\begin{tabular}{lcc}
\hline Experiment & $\mathrm{N}_{\mathrm{Na}} K_{\mathrm{s}}$ & $\log _{\mathrm{Na}}^{\mathrm{S}_{\mathrm{a}}} K_{\mathrm{s}}$ \\
\hline Variable $\left[\mathrm{Na}^{+}\right]$ & $157 \pm 7$ & 2.20 \\
Variable pH & $139 \pm 8$ & 2.14 \\
NTA & $174 \pm 9$ & 2.24 \\
\hline
\end{tabular}

With: $\left[\mathrm{Sr}^{2+}\right]$

$$
=\frac{[\mathrm{Sr}]_{\mathrm{tot}}}{\left(1+K_{\mathrm{SrL}}\left[\mathrm{L}^{2-}\right]\right)}
$$

and $\begin{cases}\{\mathrm{RCOONa}\} & =\mathrm{CEC} \\ \left\{\mathrm{RCOOSr}^{2} /[\mathrm{Sr}]_{\mathrm{tot}}\right. & =R_{\mathrm{a}}^{\mathrm{Sr}}\end{cases}$

equation (28) takes the form:

$$
\begin{aligned}
& { }_{\mathrm{Na}}^{\mathrm{Sr}} K_{\mathrm{s}}=\frac{R_{\mathrm{a}}^{\mathrm{Sr}} \cdot\left[\mathrm{Na}^{+}\right]}{\mathrm{CEC} /\left(1+K_{\mathrm{SrL}} \cdot\left[\mathrm{L}^{2-}\right]\right)} \cdot \Gamma \\
& R_{\mathrm{a}}^{\mathrm{Sr}}=\frac{{ }_{\mathrm{Na}}^{\mathrm{Sr}} K_{\mathrm{s}} \cdot \mathrm{CEC}_{\max } \cdot \alpha}{\left[\mathrm{Na}^{+}\right] \cdot\left(1+K_{\mathrm{SrL}} \cdot\left[\mathrm{L}^{2-}\right]\right) \cdot \Gamma} .
\end{aligned}
$$

Figure 6 shows the adsorption of $\mathrm{Sr}^{2+}$ (expressed as $R_{\mathrm{a}}^{\mathrm{Sr}}$ ) as a function of the NTA concentration in solution. NTA forms $1: 1$ complexes with $\mathrm{Sr}^{2+}$ with a stability constant of $\log K=5.0(\mathrm{I}=0.1 \mathrm{M})$ [14]. The adsorption experiments were carried out at $\mathrm{pH}=11$ and $\mathrm{a} \mathrm{Na}^{+}$concentration of $0.0015 \mathrm{M}$. The value of the stability constant of NTA with $\mathrm{Sr}^{2+}$ equals 5.2 at this ionic strength. At $\mathrm{pH}=11,76 \%$ of the carboxyl groups are deprotonated so that the $\mathrm{CEC}$ has a value of $1.73 \mu \mathrm{eq} / \mathrm{m}^{2}$.

The figure clearly demonstrates the inhibiting effect of NTA on the adsorption of $\mathrm{Sr}^{2+}$. The solid line in Fig. 6 represents a least square fit of $R_{\mathrm{a}}^{\mathrm{Sr}}$ as function of NTA as calculated from equation (30). Equation (30) describes the experimental results well. This is in fact not surprising since equation (30) forms the basis of the Schubert method for the determination of stability constants of complexes [16]. The ${ }_{\mathrm{Na}}^{\mathrm{Sr}} K_{\mathrm{s}}$ was derived from the least square fit and equals $174 \pm 9$.

Equation (30) is a general equation which describes the adsorption of $\mathrm{Sr}^{2+}$ as a function of $\mathrm{pH}$, ionic strength and the concentration of complexing ligands
Table 2. Composition of a standard Portland cement water SPP [17]

\begin{tabular}{lc}
\hline Parameter & Cement SPP \\
\hline Temperature [ $\left.{ }^{\circ} \mathrm{C}\right]$ & 25 \\
pH & 13.2 \\
Ionic strength [M] & 0.23 \\
$E_{\mathrm{h}}(\mathrm{mV})$ & +139 \\
$\mathrm{Na}^{+}[\mathrm{M}]$ & $6.52 \times 10^{-2}$ \\
$\mathrm{~K}^{+}[\mathrm{M}]$ & $1.61 \times 10^{-1}$ \\
$\mathrm{Mg}^{2+}[\mathrm{M}]$ & $1.00 \times 10^{-5}$ \\
$\mathrm{Ca}^{2+}[\mathrm{M}]$ & $2.25 \times 10^{-3}$ \\
$\mathrm{Fe}_{\text {tot }}[\mathrm{M}]$ & $1.00 \times 10^{-5}$ \\
$\mathrm{Al}[\mathrm{M}]$ & $2.00 \times 10^{-4}$ \\
$\mathrm{Alkalinity}[\mathrm{N}]_{\mathrm{SiO}}[\mathrm{M}]$ & $2.31 \times 10^{-1}$ \\
\hline
\end{tabular}

in solution. Depending on the chemical conditions, equation (30) can be simplified.

The values of ${ }_{\mathrm{Na}}^{\mathrm{Sr}} K_{\mathrm{s}}$ obtained from the different experiments are summarized in Table 1 . The values are very similar and it can be concluded that a value of $160(\log K=2.2)$ characterizes the adsorption of $\mathrm{Sr}^{2+}$ in presence of $\mathrm{Na}^{+}$and $\mathrm{K}^{+}$. In case of $\mathrm{Ca}^{2+}$ as counter-ion, the value of ${ }_{C_{a}}^{\mathrm{Sr}} K_{\mathrm{s}}$ is expected to be \pm 1 because of the similar chemistry of both $\mathrm{Sr}^{2+}$ and $\mathrm{Ca}^{2+}$. Complexes of carboxylic acids with $\mathrm{Ca}^{2+}$ and $\mathrm{Sr}^{2+}$ show similar stability constants [14].

Equation (30) can be used to calculate the adsorption $\left(R_{\mathrm{a}}^{\mathrm{Sr}}\right)$ of $\mathrm{Sr}^{2+}$ on bitumen under near field conditions (cementitious environment). If it is assumed that the bitumen is in contact with a cement pore water having the composition as given in Table 2 [17], then all carboxyl groups are deprotonated $(\alpha=1)$ so that the CEC value attains its maximum value of $2.3 \mu \mathrm{eq} / \mathrm{m}^{2}$. The hydrolysis reaction of $\mathrm{Sr}^{2+}$ becomes more important at this high $\mathrm{pH}\left(\mathrm{Sr}^{2+}: 80 \%\right)$; $\mathrm{Sr}(\mathrm{OH})^{+}: 20 \%$ ) but can be neglected because $\mathrm{Sr}^{2+}$ is still the dominant species. Equation (30) is thus reduced to its most simple form:

$$
R_{\mathrm{a}}^{\mathrm{Sr}}=\frac{{ }_{\mathrm{Na}}^{\mathrm{Sr}} K_{\mathrm{s}} \cdot \mathrm{CEC}_{\mathrm{max}}}{\left[\mathrm{Na}^{+}\right] \cdot \Gamma}
$$

The ${ }_{\mathrm{Na}}^{\mathrm{Sr}} K_{\mathrm{s}}$ is expected to be the same as ${ }_{\mathrm{K}}^{\mathrm{Sr}} K_{\mathrm{s}}$, so that equation (31) can be written as

$$
R_{\mathrm{a}}^{\mathrm{Sr}}=\frac{\mathrm{Sr}_{\mathrm{N}, \mathrm{K}} K_{\mathrm{s}} \cdot \mathrm{CEC}_{\max }}{\left(\left[\mathrm{Na}^{+}\right]+\left[\mathrm{K}^{+}\right]\right) \cdot \Gamma}
$$

The activity coefficient ratio $\Gamma$ is equal to 2.45 at an ionic strength of $0.22 \mathrm{M}$. A mean value of 160 for $\mathrm{Na}_{\mathrm{Na}}^{\mathrm{Sr}} K_{\mathrm{s}}$ was taken. This value, of course, is a maximum value operating at trace levels of $\mathrm{Sr}^{2+}$. At higher concentrations of $\mathrm{Sr}^{2+}$, the value of $\mathrm{Sr}_{\mathrm{Na}} K_{\mathrm{s}}$ is expected to be lower since interaction of $\mathrm{Sr}^{2+}$ with less specific surface groups might occur when the loading of the bitumen surface with $\mathrm{Sr}^{2+}$ increases. The subsequent calculations thus represent the maximum $R_{\mathrm{a}}^{\mathrm{Sr}}$ value that can be expected.

The value of $R_{\mathbf{a}}^{\text {Sr }}$ is calculated to be:

$$
R_{\mathrm{a}}^{\mathrm{Sr}}=\frac{160 \cdot 2.28 \cdot 10^{-4}}{226.2 \cdot 2.45}=7 \cdot 10^{-5} \mathrm{~cm} .
$$


Taking the effect of $\mathrm{Ca}^{2+}$ into account, the predicted $R_{\mathrm{a}}^{\text {Sr }}$ value is $<10^{-4} \mathrm{~cm}$. It may therefore be concluded that in a cementitious environment, $\mathrm{Sr}^{2+}$ exhibits negligible small sorption on the bitumen due to competitive effects of $\mathrm{Na}^{+}, \mathrm{K}^{+}$and $\mathrm{Ca}^{2+}$ present in the cement pore water.

\section{Acknowledgements}

The authors like to thank Dr. B. Baeyens, Dr. M. Bradbury and Prof. R. Grauer for the fruitful discussions. Thanks also to $R$. Keil for the chemical analysis.

This work was supported financially by the Swiss National Cooperative for the Storage of Radioactive Wastes, NAGRA.

\section{References}

1. Burnay, S. G.: Sorption effects in the leaching of ${ }^{137} \mathrm{Cs}$ from organic matrix waste forms. AERE R $12421 \mathrm{DOE} / \mathrm{RW} /$ 87.083, August 1987.

2. Hietanen Raija, Alaluusua Maarit, Jaakkola Tino: Sorption of Cesium, Strontium, Iodine, Nickel and Carbon in mixtures of concrete, crushed rock and bitumen. Report YJT85-38, 1985.

3. Alaluusua Maarit, Hakanen Martti: Sorption of Cesium, Strontium, Cobalt and Technetium in mixtures of concrete, crushed rock and bitumen. Report YJT-87-10, 1987.

4. Maes, A., van Elewijck, F., Vancluysen, J., Tits, J., Cremers, A.: Cobaltihexammine as an index cation for measuring the cation exchange capacity of humic acids. Proceedings of the International Symposium on Humic Substances in the Aquatic and Terrestrial Environment, Linkoping, Sweden, August 21-23, 1989. In Press in Lecture Notes in Earth Sciences.

5. Dalang, F.: Zur Adsorption von Kationen an die Metalloxid-Wasser-Grenzfläche: Die Adsorption von robusten Kobaltkomplexen. Ph. D. Thesis, Diss. Nr. 5916, ETH Zürich, Switzerland 1977.

6. Morel, R.: Etudes expérimentales des phénomènes d'échange sur differentes minéraux argileux. Ann. Agron. 6, 5-90 (1975).

7. Eldridge, R. J., Treloar, F. E.: Binding of counterions to polyacrylate solutions. J. Phys. Chem. 74, 1446-1449 (1970).

8. Takamura, K., Chow, R. S.: The Electric Properties of the Bitumen/Water Interface, Part II: Application of the Ionizable Surface-Group Model. Colloids Surf. 15, 35-48 (1985).

9. Danielli, J. F.: The Relations between Surface pH, Ion Concentrations and Interfacial Tension. Proc. R. Soc. London, Ser. B, 122, 155-174 (1937).

10. Stone-Masui, J., Watillon, A.: Characterization of Surface Charge on Polystyrene Latices. J. Colloid Interface Sci. 52, 479-503 (1975).

11. Diamond, R. M., Whitney, D. C.: Resin selectivity in dilute to concentrated aqueous solutions. In: Ion exchange, Volume I, (J. A. Marinsky, ed.), Marcel Dekker, In., New York 1966.

12. Novozamsky, I., Beek, J., Bolt, G. A.: Chemical Equilibria. In: Soil Chemistry, A: Basic elements (G. Bolt and M. Bruggenwert, eds.), Elsevier Scientific Publishing Company. Amsterdam-Oxford-New York 1978.

13. Buffle, J.: Complexation Reactions in Aquatic Systems: an Analytical Approach, 1st ed., Ellis Horwood Limited 1988, p. 692.

14. Sillen, L. G., Martell, A. C.: Stability constants of metalion complexes, Special Publication 25, Chemical Society, Burlington House, W1 London 1971.

15. Perdue, E. M., Reuter, J. H., Parrish, R. S.: A Statistical Model of Proton Binding by Humus. Geochim. Cosmochim. Acta 48, 1257-1263 (1984).

16. Van Loon, L. R., Kopajtic, Z.: Complexation of $\mathrm{Cu}^{2+}, \mathrm{Ni}^{2+}$ and $\mathrm{UO}_{2}^{2+}$ by radiolytic degradation products of bitumen, PSI report no. 66, Würenlingen and Villigen, Switzerland 1990.

17. Anderson, $\mathrm{K}$.: Transport of radionuclides in Water/Mineral systems. Ph. D. Thesis, ISBN 91-7032-105-1, Chalmers University, Goteborg 1983. 